\title{
Sušenje sestoja rdečega bora nad Belco v letu 2015
}

\author{
Nikica OGRIS $^{1^{*}}$, Andreja KAVČIČ ${ }^{1}$
}

Oktobra 2015 smo nad naseljem Belca v Občini Kranjska Gora opazili sušenje rdečega bora (Pinus sylvestris L.) (sliki 1 in 2). Sušenje dreves je bilo prisotno na območju s krajevnim imenom Štenge (GKX = $416.629 \mathrm{~m}, \mathrm{GKY}=149.232 \mathrm{~m}$, gozdni odsek $020558 \mathrm{~V}$ in $020559 \mathrm{~V}$ ) na površini 1,9 ha (slika 3). Območje sušenja se je raztezalo od nadmorske višine $922 \mathrm{~m}$ do 1017 $\mathrm{m}$ nad morjem. Naklon pobočja na območju, kjer smo opazili sušenje, znaša med $8^{\circ}$ in $54^{\circ}$ (povprečni naklon $38^{\circ}$ ) (GURS, 2006). Zaradi velikega naklon terena je to območje določeno kot varovalni gozd (ZGS, 2015). Kamninsko podlago sestavljajo masiven in skladnat dolomit in apnenec ter pobočni grušč (GEOZ, 2002). Kamnitost in skalovitost terena je velika in znaša 40-60\%. Tla so plitva, sestavlja jih prhninasta rendzina (PEDKRS, 1999). Sušenje rdečega bora na tem območju se je v preteklosti že pojavilo, in sicer leta 2011 na manjšem območju približno $200 \mathrm{~m}$ zahodno od območja, kjer se je sušenje pojavilo letos (slika 1).

Območje, kjer se je pojavilo sušenje rdečega bora predstavlja ekstremno rastišče zaradi velikega naklona terena, dolomitne podlage ter plitvih tal, saj je kapaciteta takšne podlage za zadrževanje vode zelo nizka. Zaradi nizke sposobnosti zadrževanja vode take podlage lahko zelo hitro nastopi sušni stres, ki povzroči upad vitalnosti dreves. Leto 2015 je zaznamovalo nadpovprečno toplo in suho poletje s pomanjkanjem padavin (ARSO, 2015). Glede na to sklepamo, da je na prizadetem območju prišlo do sušnega stresa, ki je povzročil upad vitalnosti dreves in s tem oslabil njihove obrambne mehanizme za zaščito pred boleznimi in škodljivci. Manj vitalna drevesa so podlegla sekundarnim škodljivim organizmom in fakultativnim parazitom, ki jim pravimo tudi paraziti šibkosti. V prizadetem sestoju smo na še živih drevesih opazili močne okužbe z glivo Diplodia pinea (Desm.) J. Kickx, ki povzroča bolezen z imenom sušenje najmlajših borovih poganjkov (slika 4). Na odpadlih storžih so bili v velikem številu razviti črni piknidiji te glive, kar pomeni, da v obravnavanem sestoju rdečega bora obstaja velik inokulacijski potencial te glive. V skorji odmrlih rdečih borov smo našli rizomorfe mraznice ali štorovke (Armillaria spp.) (slika 5), rove in ličinke kozličkov (Cerambycidae) (slika 6) ter rove in izhodne odprtine krasnikov (Buprestidae) (sliki 7 in 8). Čeprav so štorovka, kozlički in krasniki v nekaterih primerih lahko primarni škodljivci, ki sprožijo upad vitalnosti dreves, jih v opisanem primeru uvrščamo med sekundarne škodljivce. Predvidevamo namreč, da so naselili drevesa, ki so že bila oslabljena zaradi sušnega stresa. Na približno 30 \% posušenih dreves smo opazili luščenje in odpadanje skorje, zlasti $\mathrm{v}$ krošnji in $\mathrm{v}$ zgornjem delu debla (slika 8). Odpadanje skorje so pospešile ptice s kljuvanjem pri iskanju žuželčjih ličink in bub. Da območje nad Belco predstavlja ekstremno rastišče potrjujejo tudi ostanki razmeroma velikega števila dreves, ki so se posušila že v preteklosti (slika 9). Nekatera od njih so vidna tudi na ortofoto posnetku iz leta 2011 (slika 3).

V zadnji letih je Poročevalska, prognostično-diagnostična služba za gozdove Gozdarskega inštituta Slovenije prejela več obvestil s strani Zavoda za gozdove Slovenije o sušenju rdečega bora na več lokacijah po Sloveniji, predvsem iz gozdnogospodarskih območij Sežana, Tolmin in Ljubljana (de Groot in sod., 2015). Vsem obvestilom so skupni zelo podobni simptomi, tj. hiranje in sušenje rdečega bora na velikih površinah, prisotnost kozličkov in krasnikov pod lubjem ter poškodbe krošnje zaradi sušice najmlajših borovih poganjkov. Na podlagi opravljenih terenskih pregledov in laboratorijskih analiz škodljivih organizmov smo mnenja, da so v vseh opaženih primerih primarni vzrok sušenja borov izredno vroča in suha poletja ter neustrezno rastišče, ki ima majhno kapaciteto zadrževanja vode. Zaradi tega na teh rastiščih drevje pogosteje prizadene sušni stres, ki izrazito negativno vpliva na vitalnost in odpornost dreves. Oslabela drevesa lahko okužijo številne glive, ki se $\mathrm{v}$ vitalnih drevesih ne morejo razvijati in povzročiti bolezen ter napadejo jih škodljivci, ker so obrambni mehanizmi drevesa preslabotni. Končni učinek združenega delovanja vseh škodljivih dejavnikov je propad dreves.

Ker gre za varovalni gozd, ki zadržuje prenaglo odtekanje vode in zato varuje zemljišča pred erozijo in plazovi, mora Zavod za gozdove Slovenije zagotoviti pravočasen posek odmrlega drevja (Uredba o varovalnih ..., 2005). Posekana drevesa moramo nujno odstraniti z območja, saj imamo v neposredni bližini hudournike. V nasprotnem primeru bi $\mathrm{z}$ veliko verjetnostjo prišlo do prevračanja dreves s koreninami vred, kar bi posledično vodilo $\mathrm{k}$ pospešeni eroziji tal. Pri poseku obolelih dreves moramo pustiti primerno visoke panje, ker gre za območje nevarnosti snežnih plazov. Že poškodovana tla bi morali sanirati zaradi preprečevanja nadaljnje erozije. Da bi trajno dosegli večjo stabilnost tal, bi po poseku morali nujno posaditi nove rastline; poleg obstoječega rdečega bora in macesna bi bile ustrezne še sadike drugih drevesnih vrst, ki so prilagojene po eni strani na sušo in vročino po drugi strani pa na sneg in mraz, kot je npr. črni gaber (Ostrya carpinifolia Scop.).

\section{Zahvala}

Zahvaljujemo se recenzentu prof. dr. Dušanu Jurcu za bistvene izboljšave članka.

\section{Viri}

ARSO. 2015. Naše okolje - Bilten Agencije RS za okolje, 22, št. 6-9 de Groot M., Ogris N., Kavčič A. 2015. Poročilo o preskusu št.: U2015-017. Laboratorij za varstvo gozdov, Gozdarski inštitut Slovenije: 11 str.: http://www.zdravgozd.si/dat/pdp/U2015017.pdf GEOZ. 2002. Osnovna geološka karta Slovenije v merilu $1: 100000$. 2002. Ljubljana, Geološki zavod Slovenije 
GURS. 2006. Digitalni model višin 12,5 m. Geodetska uprava Republike Slovenije

PEDKRS. 1999. Pedološko rekartiranje in digitalizacija pedoloških kart Republike Slovenije v merilu 1:25.000 kot osnove za določitev talnega potenciala: digitalna pedološka karta, pedološki profili. Ljubljana, Univerza v Ljubljani, Biotehniška fakulteta, Oddelek za agronomijo, Center za pedologijo in varstvo okolja: 20 str.

Uredba o varovalnih gozdovih in gozdovih $\mathrm{s}$ posebnim namenom (Uradni list RS, št. 88/05, 56/07, 29/09, 91/10, 1/13 in 39/15)

ZGS. 2013. Gozdni fondi. Podatkovna zbirka. Zavod za gozdove Slovenije

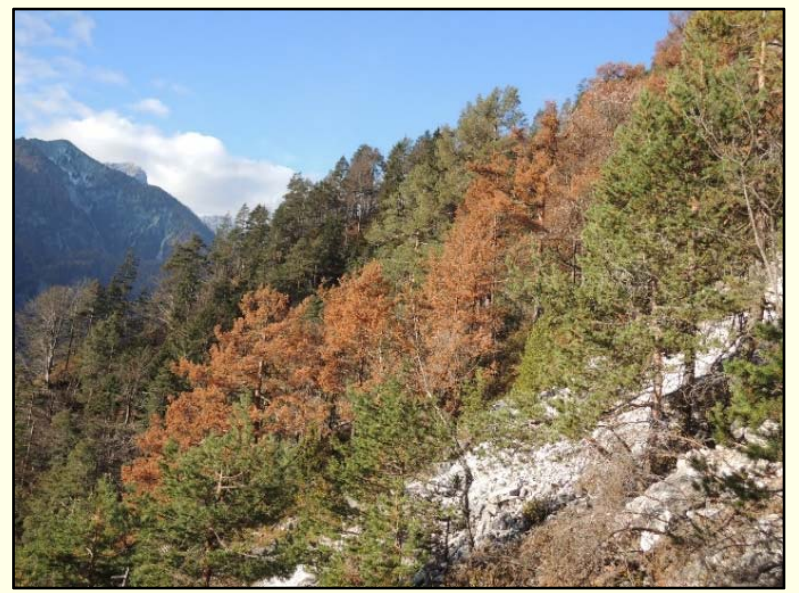

Slika 1: Sušenje rdečega bora nad Belco v letu 2015 (zahodni rob območja; foto: N. Ogris)

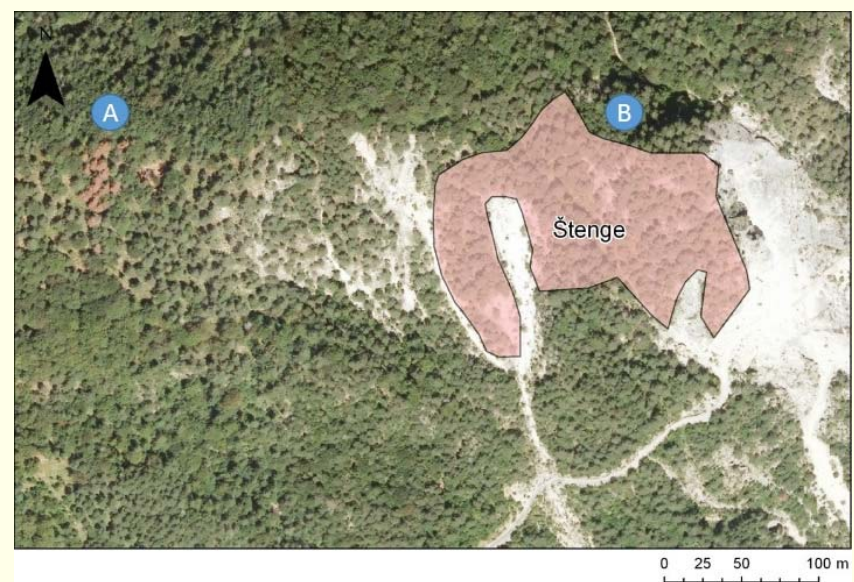

Slika 3: Območje sušenje rdečega bora nad Belco v letu 2011 (A) in v letu 2015 (B) (Ortofoto posnetek GURS 2011, karto pripravil N. Ogris)

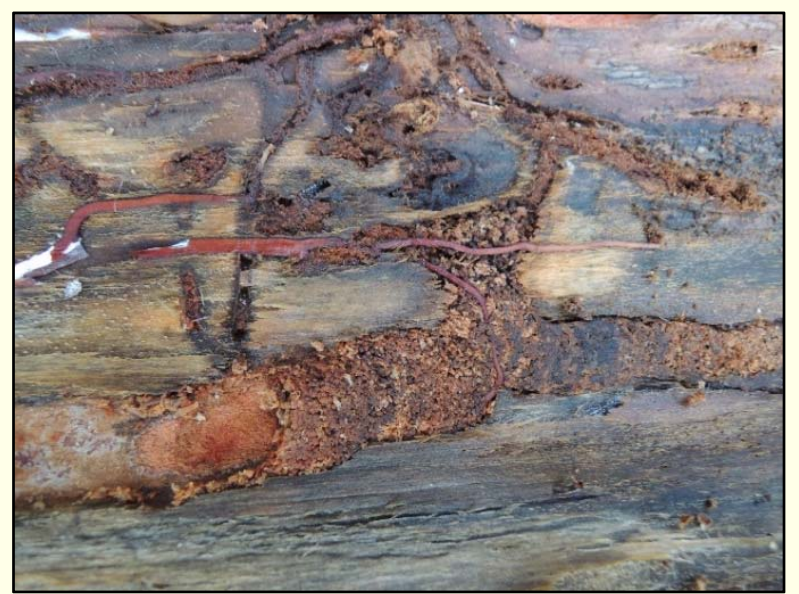

Slika 5: V odmrlih rdečih borih so pod skorjo razraščeni rizomorfi mraznice (Armillaria) in izžrti rovi kozličkov (Cerambycidae) in krasnikov (Buprestidae) (foto: N. Ogris)
ZGS. 2015. Varovalni gozdovi v Sloveniji. Zavod za gozdove Slovenije, 2015, grafični sloj

*Gozdarski inštitut Slovenije, Večna pot 2, 1000 Ljubljana nikica.ogris@gozdis.si

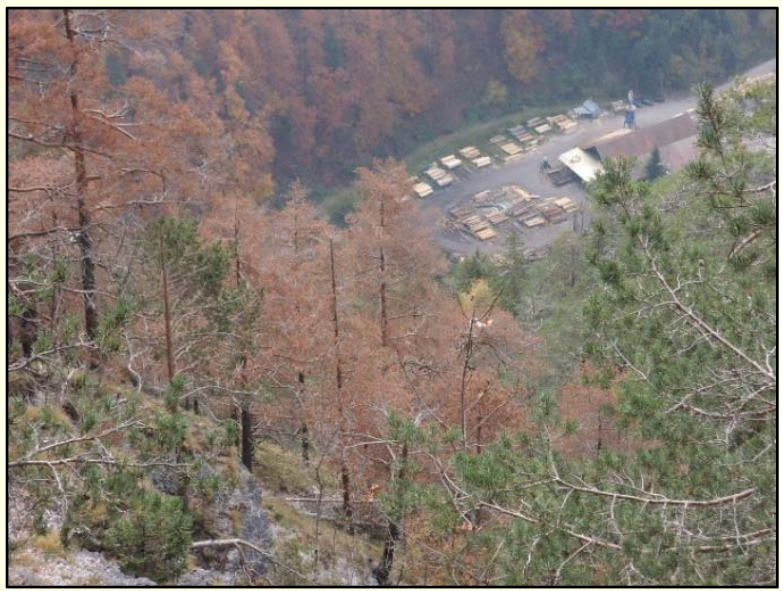

Slika 2: Sušenje rdečega bora nad Belco v letu 2015 (vzhodni rob območja, v ozadju žaga v Belci; foto: N. Ogris)

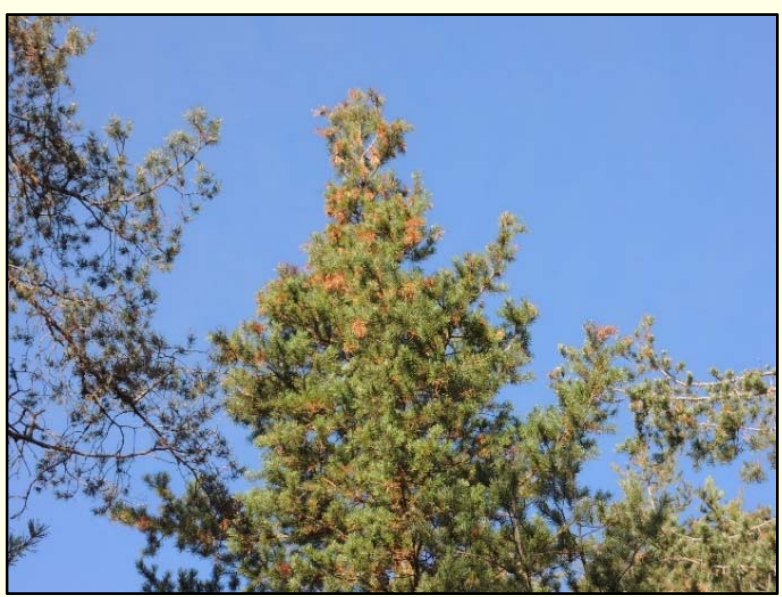

Slika 4: Sušenje najmlajših borovih poganjkov je povzročila gliva Diplodia pinea (foto: N. Ogris)

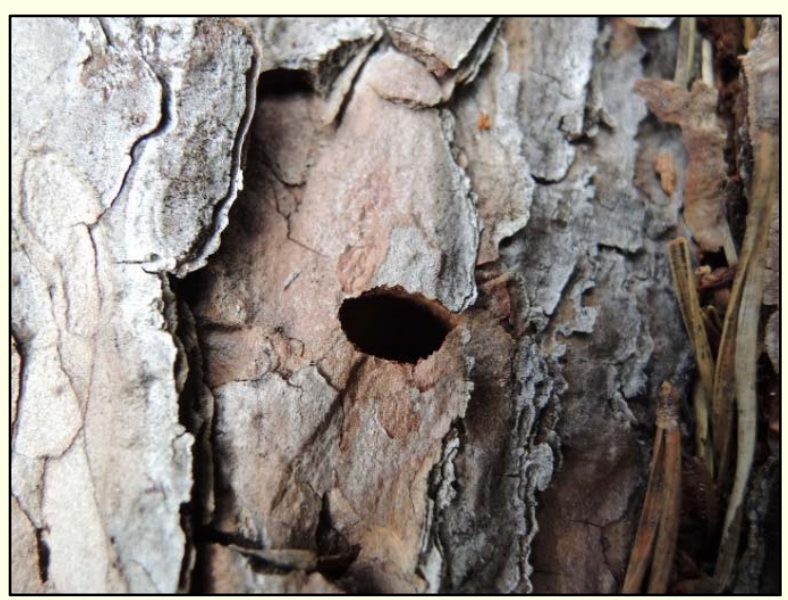

Slika 6: Značilna izhodna odprtina na skorji v obliki velike črke D, ki jo izdela krasnik (Buprestidae) (foto: N. Ogris) 


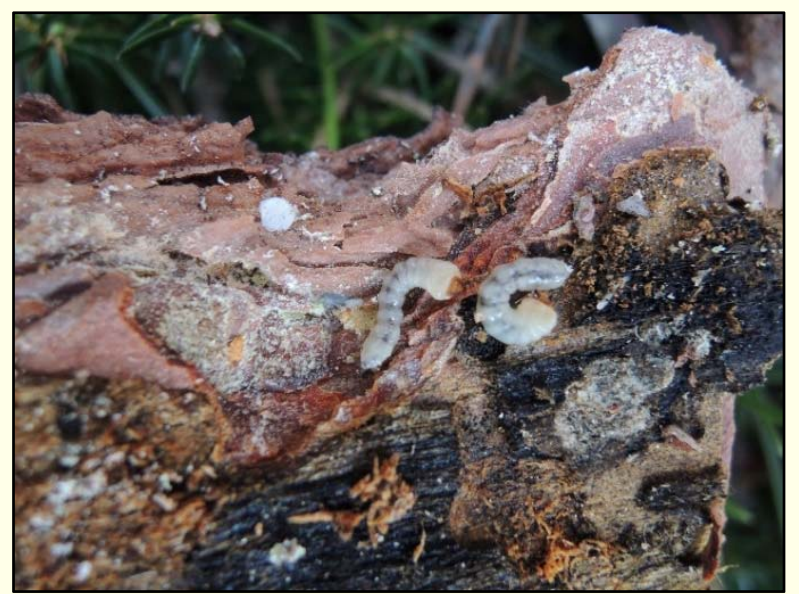

Slika 7: Ličinki kozlička (Cerambycidae) (foto: N. Ogris)

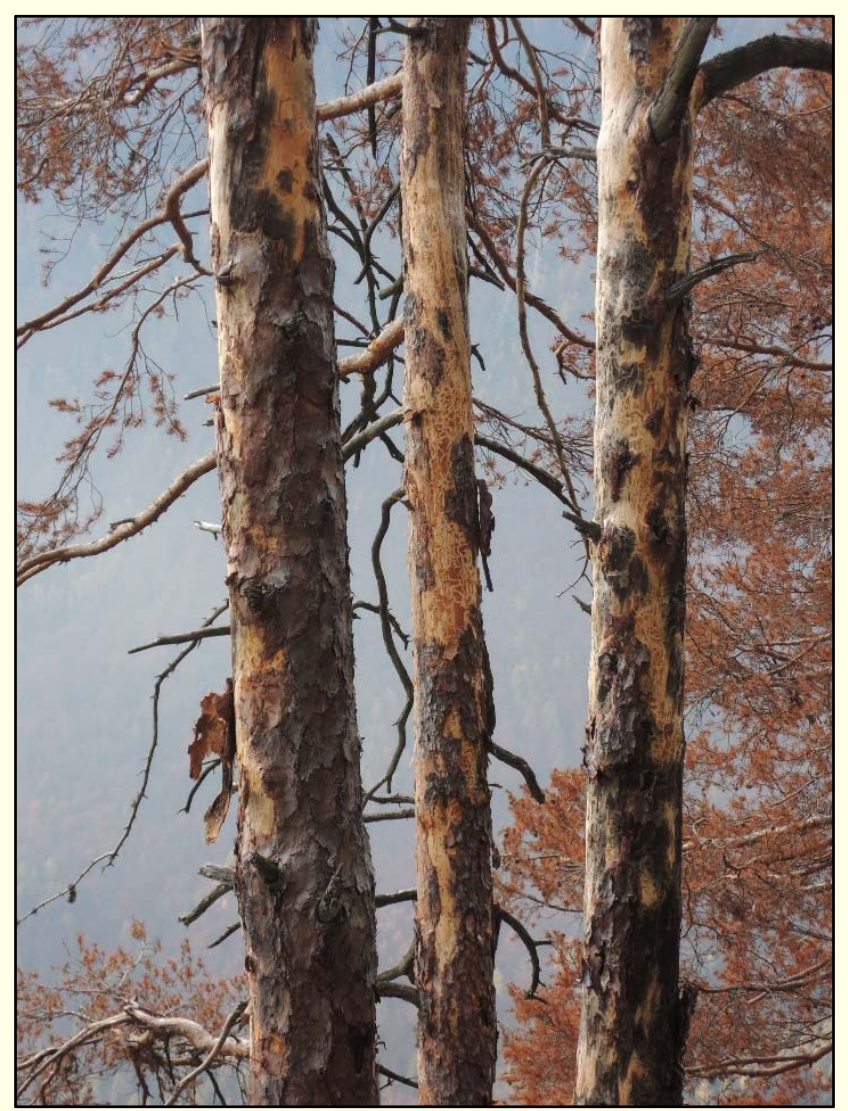

Slika 8: Skorja odmrlih rdečih borov je pričela odpadati (foto: N. Ogris)

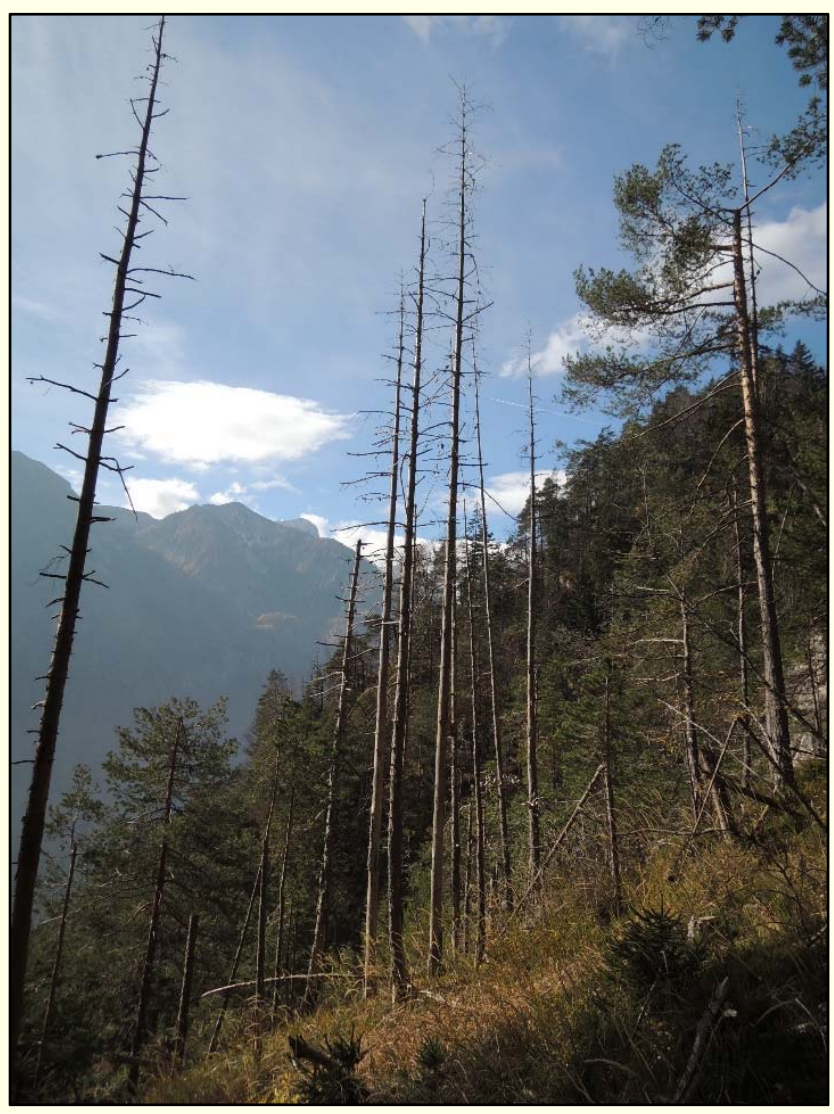

Slika 9: Skupina rdečih borov, ki je odmrla že pred več leti (foto: N. Ogris) 